\title{
Phthalates: Potential sources and control measures
}

\author{
M. Grinbaum ${ }^{1}$, A. Camponovo ${ }^{2}$, J.-M. Desseigne, P. Poupault, E. Meisterman, B. Chatelet, F. Davaux, and V. Lempereur \\ ${ }^{1}$ Institut Français de la Vigne et du Vin, Institut Rhodanien, 2260 Route du Gres, 84100 Orange, France \\ ${ }^{2}$ Institut Français de la Vigne et du Vin, Centre du Rosé, 70 Bd Wilson, 83550 Vidauban, France
}

\begin{abstract}
The issue of endocrine disruptors is a subject of debate in the agri-food sector and questioning for consumers through the media. Among these compounds, some of the family of phthalates, are used in the composition of some materials used in wineries. This makes it a worrying issue in terms of image and safety. The objective ok this work was to identify the sources of phthalates and the factors favoring their diffusion in wines to propose preventive and curative solutions to the wine makers. The modalities were therefore selected in different French wine regions to represent the diversity of oenological practices. This survey also led to examine more thoroughly the parameters involved in the situations that favored migration of the highest levels. Additional experiments were performed specifically on certain sources or contributing factors. The first identified sources include epoxy resin, fiberglass reinforced polyester as well as PVC materials (pipes ...). Favorable factors include alcohol content, temperature, duration and contact area.
\end{abstract}

\section{Introduction}

\subsection{Context}

Materials can exchange compounds with wines that come into contact with them. This property used advantageously during ageing in barrels or oenological treatments as filtrations, can become binding when it occurs as an unwanted effect. Indeed, some equipment can let disperse compounds potentially detrimental to health. Among all the compounds concerned, several coming from plastic materials have been quoted for their endocrine disruptor effect and constitute the phthalate family.

The issue of endocrine disruptors is a subject of debate in the agri-food sector and questioning for consumers through the media. This makes it a worrying issue in terms of image and safety. Therefore, it appeared as primordial to get orders of magnitude that could be encountered in the wine sector and list the potential sources to help producers to identify if they could be concerned and to control this risk all along the process.

\subsection{Compounds studied}

Phthalates are widely used as additives as plasticizers in the manufacture of almost all polyvinyl chloride (PVC) products, to which they provide the desired flexibility. They are used in a large number of everyday objects (diapers, shoes, boots, waterproof textiles, shower curtains, toys, game consoles, printing inks, glues, lubricants, detergents ...) including materials used in wine cellars (pipes, tanks, ...).

It is a chemical family of several dozen derivative compounds (salts or esters) of phthalic acid. They all share a common chemical structure (Fig. 1). They are composed of a benzene ring and of two carboxylate groups placed in ortho. The size of the carbon alkyl chain may be longer or shorter. Phthalates can thus be classified according to their molecular weight (Table 1).
In pure form, phthalates are generally viscous organic liquids, very little volatile, clear, transparent, colorless and odorless. Hydrophobic under normal conditions, they are very insoluble in water and have a particular affinity for fats and alcohols. They are thus found in foods (milk, cheese, fish, meat, margarine, cereals, alcoholic beverages...) partly as a result of their migration from contact materials or food packaging. Wines are concerned by several phthalates but the DnBP, concentrates most of the concerns.

Levels encountered in wines. Some laboratories' results indicated high levels in several products. However, the conditions that lead producers to carry out this expensive analysis are most often linked initially to a suspicion of risk. It can therefore be reasonably assumed that published values give rather an image of the extreme values that can be encountered but not of the actual distribution of the contents.

\subsection{Impact on health}

The ANSES (French food safety authority) has classified certain phthalates (DEHP, DnBP, BBP) in the category CMR (carcinogenic, mutagenic, reprotoxic) $1 \mathrm{~B}$, that is to say that they could have negative effects on human reproduction. Some are described in toxicology as having endocrine disrupting effects (decrease in fertility, testicular atrophy, reduction of fetal weight, fetal mortality, malformations, ...).

Children are more exposed because they absorb more food than adults in relation to their body weight and because they carry plastic objects in their mouths. The classifications of these molecules is an ongoing debate among scientific bodies. In France, if the ADI (Acceptable daily intake) is exceeded for one of the compound, the wine can't be marketed [1].

The ADI represents for man the maximum amount of a substance that he can ingest daily throughout his 


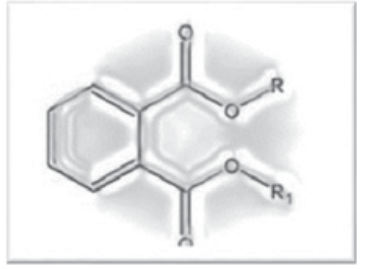

Figure 1. Chemical structure of phthalates.

Table 1. Molecular weight of main phthalates encountered in the wine sector.

\begin{tabular}{|l|c|c|}
\hline Acronym & Phtalate & $\begin{array}{c}\text { Molecular } \\
\text { weight }(\mathbf{g})\end{array}$ \\
\hline DMP & (di-methylphtalate) & 194.18 \\
\hline DEP & (di-ethylphtalate) & 222.24 \\
\hline DIBP & (di-isobutylphtalate) & 278.35 \\
\hline DnBP & (di-nbutylphtalate) & 278.34 \\
\hline BBP & (benzylbutylphtalate) & 312.26 \\
\hline DEHP & (di-2-ethylhexyl phtalate) & 390.57 \\
\hline DnOP & (di-n-octylphtalate) & 390.56 \\
\hline DINP & (di-iso-nonyl phthalate) & 420.6 \\
\hline DIDP & (di-iso-decylphthalate) & 446.7 \\
\hline
\end{tabular}

life without risk to his health. It is the chronic toxicity reference that is used in the calculation of the risk assessment for human health in the long term. The ADIs can be consulted on the website of EFSA (European Food Safety Agency). The most commonly used criteria for risk analysis are those of EFSA's PRIMo model: a daily consumption of $264 \mathrm{~mL}$ of wine per $60 \mathrm{~kg}$ person.

\subsection{Regulation}

According to regulation (UE) $n^{\circ} 1935 / 2004$, materials and articles intended to come into contact with foods materials shall be manufactured so that they do not transfer their constituents to food in quantities which could endanger human health (article 3).

As well, the traceability of materials and articles shall be ensured at all stages in order to facilitate control, the recall of defective products, consumer information and the attribution of responsibility (article 17).

Specific measures apply to plastics and are described in the Regulation (EU) $n^{\circ} 10 / 2011$. The use of certain phthalates (DMP, DnOP, DEP, DIBP, DCHP) is not allowed for materials in contact with food. Their content mustn't exceed an analytical limit (Table 2).

Nevertheless, they can be used in other materials non suitable for food contact. Five others phthalates (DEHP, BBP, DnBP, DINP and DIDP) are allowed intentionally as plasticizers in the manufacture of materials, under certain conditions and are assigned specific migration limits (SML).

Exceeding this value is considered as the sign that a wine was set in contact with one or several inappropriate materials or in inappropriate conditions. It requires to find the source of the migration to reduce it.

It should be noted that alcoholic beverages containing more than $20 \%$ by volume (and liqueurs containing cream) are assimilated to fatty foods according to Regulation (UE) $\mathrm{n}^{\circ} 10 / 2011$. So, this 5 phthalates should not be used in the composition of plastic materials in contact with this type of beverage.
Some compounds are also restricted for example for non-fat foods. Similarly, the regulation (UE) $n^{\circ} 10 / 2011$ defines an overall migration limit for plastic materials: they shall not transfer their constituents to food simulants in quantities exceeding 10 milligrams of total constituents released per $\mathrm{dm}^{2}$ of food contact surface (article 12).

\section{Method}

\subsection{General organisation}

This study was concomitant with the redaction of the good hygiene practice guide by French wine sector [2,3]. In this document the description of good practices about materials were strongly reinforced but questions remained about plastic materials.

Phthalates have been identified by IFV (French institute of vine and wine) and some professional partners as emerging contaminants requiring monitoring in view of improving recommendations in this area. No studies were conducted on the quantification of these compounds at different stages of wine making. Only, some isolated data from laboratories reported that SML were occasionally exceeded. IFV therefore coordinated a technical study led between 2012 and 2017 by a working group of 8 partners including producers, interprofessionnals organizations and laboratories.

The objective was to identify the main sources of migration by studying the levels and nature of phthalates that could be encountered throughout the winemaking process. The results will be used to improve recommendations to control and reduce contaminations.

\subsection{Selection of the process}

Two kinds of protocols were implemented: follow ups of technical itineraries and specific studies on equipment.

Follow-ups consisted in observing the musts then wines throughout different technical itineraries on several production sites, in real conditions.

Representative samples were taken for analysis at 4 stages: must, end of alcoholic or malolactic fermentation, end of the ageing period and after conditioning.

At the same time the experimenters reported on site: the cultivation method in the vineyard (organic, conventional, biodynamic), the harvesting method (manual or mechanical), the type of vinification (red, rosé, white, thermovinification, sweet wines, sparkling wines) and the equipment used in the wine making process, with particular attention to the vat room (stainless steel, raw concrete, concrete coated with epoxy resins or glass tiles, glass fiber reinforced polyesters, wooden container ...).

Specific studies were performed on equipment identified as potential sources of contamination during the previous follow ups: concrete tanks coated with epoxy resin, fiberglass reinforced polyester tanks, flexible pipes, filtration equipment.

These experiments were carried out either on production sites or in experimental cellars. Studies have also been carried out on the incidence of the final container (glass bottles, PET, bag-in-box) and shutters. A total of 800 samples from either technical itineraries or specific studies were analyzed between 2012 and 2017. 
Table 2. Limits and conditions of use according Regulation (UE) n ${ }^{\circ}$ 10/2011.

\begin{tabular}{|c|c|c|c|}
\hline Phthalates & SML (mg/kg) & ADI mg/kg body weight /day & Conditions of use \\
\hline DnBP & 0.3 & 0.010 & \multirow[t]{2}{*}{$\begin{array}{l}\text { Authorised for use contact with } \\
\text { non fatty foods }\end{array}$} \\
\hline DEHP & 1.5 & 0.050 & \\
\hline BBP & 30 & 0.500 & \multirow[t]{3}{*}{$\begin{array}{l}\text { Authorised for use in contact } \\
\text { with non-fat foods except infant } \\
\text { preparation }\end{array}$} \\
\hline DINP & \multirow{2}{*}{$9(\mathrm{DINP}+\mathrm{DIDP})$} & 0.150 & \\
\hline DIDP & & 0.150 & \\
\hline DMP & \multirow[t]{5}{*}{$<0.01$ (analytical limit) } & - & \multirow[t]{5}{*}{ Not allowed in food } \\
\hline DnOP & & - & \\
\hline DEP & & - & \\
\hline DIBP & & - & \\
\hline DCHP & & - & \\
\hline
\end{tabular}

\subsection{Phthalates analysis}

\subsubsection{Sampling, preparation}

Particular care must be taken in sampling to avoid possible contamination with environmental sources of phthalates. Wine sampling in vats can be made using a glass bottle with a stainless steel plunger placed in the middle of the tank. Then the contents of the bottle are distributed in glass vials, with phthalates-free caps for sending to the laboratory.

Polyvinyl chloride (PVC) plastic bottles and high density polyethylene (HDPE) couldn't be used because of the risk of release of phthalates for the first one or adsorption for the second one.

Another difficulty in the determination and analysis of phthalates lays in these compounds being frequently present as plasticizers in the analytical equipment, the solvents as well as in the air of the laboratories. Hence it is necessary to subtract a "blank" from the results.

\subsubsection{Method of analysis}

The international reference method (OIV-MA-AS323-10type IV; resolution OIV-OENO 477-2013), for the analysis of phthalates in wines is gas chromatography, coupled to mass spectrometry (GC-MS or GC-MSMS) after liquidliquid extraction with a non-polar solvent.

Although it is very sensitive and selective, for the majority of phthalates, this analytical method has certain limits: it is sensitive to the TAV of samples; the extraction yields are very different from one compound to another; the preparation of stock solutions is done in hexane; the heavier phthalates (case of DINP and DIDP) are very difficult to analyze. For the latter, a better analytical performance is obtained by liquid chromatography analysis coupled to a mass spectrometer (LC-MSMS) by direct injection of the wine.

The list of the compounds analyzed in the framework of the study is given in the Table 3. The analytical limits are also specified.

\section{Results}

Although the LMS are expressed in $\mathrm{mg} / \mathrm{L}$, given the low concentrations measured in wines, and in order to maximize readability in the tables and figures presented below, all the results are expressed in $\mu \mathrm{g} / \mathrm{L}$.
Table 3. Compounds studied in the project. LOD: Limit of Detection, LOQ: Limit of Quantification.

\begin{tabular}{|c|c|c|}
\hline Acronym & LOD $(\mu \mathrm{g} / \mathbf{L})$ & $\mathbf{L O Q}(\boldsymbol{\mu g} / \mathbf{L})$ \\
\hline DnBP & 1 & 2.5 \\
\hline DEHP & 1 & 2.5 \\
\hline BBzP & 0.5 & 1 \\
\hline DINP & 5 & 10 \\
\hline DIDP & 2 & 10 \\
\hline DMP & 0.5 & 2.5 \\
\hline DnOP & 1 & 2.5 \\
\hline DEP & 0.5 & 2.5 \\
\hline DIBP* & 1 & 2.5 \\
\hline DCHP & 1 & 2.5 \\
\hline
\end{tabular}

\subsection{Follow ups of technical itineraries}

A total of 97 technical itineraries were studied, among which 24 with complete traceability from grapes to conditioned wine. 15 were studied from the end of alcoholic fermentation to conditioned wine.

When a complete traceability could not be obtained, particularly because of blending, only conditioned wines were analyzed.

The whole represents around 300 samples on the period from 2012 to 2015. An example is given in the Table 4.

On musts, results underline that steps before fermentation are not contaminating steps. Among 44 samples, 2 contained quantifiable traces of phthalates (BEHP, DINP), that were not find on wine any more. The low risk of migration at this step can be explained by he by the hydrophobic properties of the molecules and their low solubility in aqueous phase. Furthermore, the contact time between grapes or must and an equipment is usually limited before fermentation.

On wines the DnBP was the phthalate most often encountered in the study. The BBP was less frequent, usually at very low concentrations, and very occasionally DEHP, DINP and DIDP.

The presence of DnBP was usually linked to the storage in tanks coated with epoxy resins. There was little or no trace of this molecule in process with only stainless steel tanks or wood.

Contaminations could be observed from the end of the alcoholic fermentation, but at values that didn't exceed the LMS in our study. After several months of ageing, in some epoxy coated tanks DnBP levels increase significantly. 
Table 4. Example of a follow up of red wine vinification process.

\begin{tabular}{|c|c|c|c|c|}
\hline \multirow{2}{*}{ Stage } & \multirow{2}{*}{ Main equipment } & \multicolumn{3}{|c|}{ Phthalates level $(\boldsymbol{\mu g} / \mathbf{L})$} \\
\cline { 3 - 5 } & & DnBP & BBP & DEHP \\
\hline Must & Harvesting machine, receiving equipment & nd & nd & nd \\
\hline Wine after FML & Epoxy coated tank, screw press, transfer equipment & 161 & 10 & nd \\
\hline Wine after ageing & Filters, transfer equipment, stainless steel vat & 204 & 20 & 37 \\
\hline Glass bottle & Filters, pumps and bottling chain & 219 & 20 & $<5$ \\
\hline
\end{tabular}

The presence of forbidden phthalates was detected in several technical itineraries including polyester tanks reinforced with fiberglass tiles. Thus, DMP (banned phthalate) has been found in large quantities in some wines aged 18 months in fiberglass tanks. However, additional tests on other fiberglass tanks in cellars did not show migration of this molecule. These observations suggest that release can be effective in certain old tanks without allowing to define a typology with regard to the age or to the provider of the equipment.

Overall, according to the results of this study, the conditioning in glass or PET (polyethylene terephthalate) bottle, is not a major step in terms of phthalate migration.

In some cases, small reductions or small increases in phthalate levels in the wines were identified after filtering. In bag-in-box, significant reductions were observed after several months.

\subsection{Experimentations on vats coated with epoxy resins}

Epoxy resins are used to coat concrete or steel vats. Their composition vary according to the manufacturer and phthalate free coatings are even available since 2005.

DnBP migration kinetics were carried out on epoxy resin tanks containing phthalates. They were all around 10-15 years old in the wineries and applied by the same company (Fig. 2).

The level of DnBP in wines, stored in the vats of several wineries was followed during all the contact time, between 6 months and up to 14 months for $\mathrm{C} 1$. The first point of each kinetic corresponds to the date of the filling of the tank. The experimentation ended when the wine was removed.

In the whole cases an increasing of DnBP throughout the storage period was observed. After respectively 6 and 10 months, S6 and C1 exceeded the SML of DnBP which is $300 \mathrm{~g} / \mathrm{L}$. For $\mathrm{S} 15, \mathrm{R} 13$ and R16, the contamination was moderate. However, if the observed trend had been confirmed during a longer period of storage, the SML would have been be reached at respectively 8,12 and 11 months.

Moreover, at the filling of the tank at blending, most of wines already contained DnBP in variable concentrations. The highest initial value was observed in S15. As it could be supposed that DnBP was not present on must nor in transport dump funds, the origin had to be searched in the cellar, before assembly.

The level of DnBP in S15, R13 and R16 was still lower than the SML after 6 months of contact. The rate of enrichment calculated in linear phases is around $1.5 \mu \mathrm{g} / \mathrm{L} /$ day. The product remains marketable because this value is under the ADI.

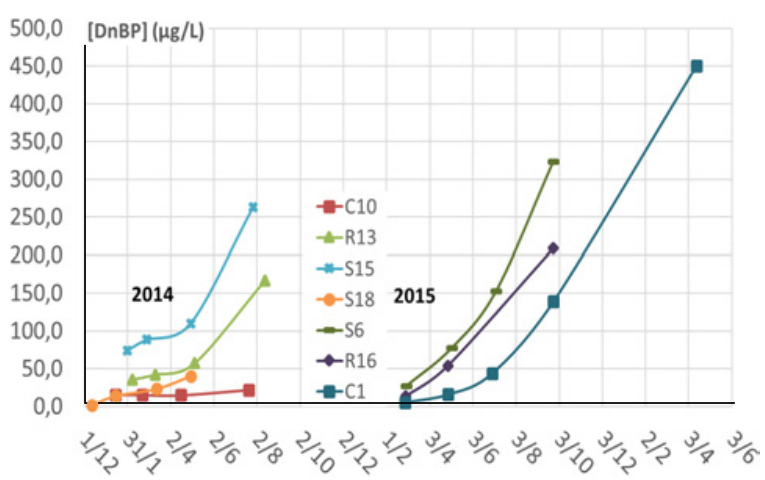

Figure 2. DnBP migration kinetics in wines from epoxy resin coated tanks, from the same provider, in several wineries (2014 ant 2015). The first point corresponds to the filling of each tank.

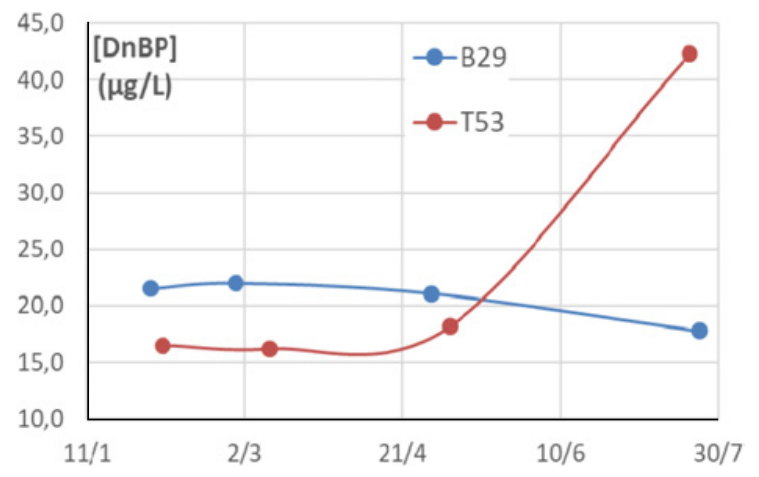

Figure 3. DnBP migration kinetics in epoxy resin coated tanks allegedly "phtalates free", in use in two wineries. B29: effectively phtalates free, T53: not phthalate free.

The DnBP migration kinetics curves show an inflection towards the April-May period. The increase in the release rate is probably related to the temperature rise at spring.

The impact of temperature was verified on an epoxy coating by performing more precise measurements in a cellar.

Experimentations have also been performed on two vats recently coated (Fig. 3). A DBP migration kinetics were carried out on two tanks coated with epoxy resins allegedly "phthalate free".

The decision to make this test was taken following some difficulties to get attestations of conformity to regulation from suppliers.

The tank B29, was effectively phthalate free and didn't release DnBP. Thus the contamination can be avoided by using this kind of coatings.

The tank T53 was responsible of the increase of DnBP in the wine. Even is the release was low, this equipment was made with phthalates compounds and the provider shouldn't have mentioned "phthalate-free" on his commercial documents. At the same time, this equipment 
Table 5. Enrichment of a wine in phthalates during a transfer by pumping, in a closed circuit $(70 \mathrm{hL} / \mathrm{h})$ constituted of $10 \mathrm{~m}$ of flexible PVC pipe (diameter $50 \mathrm{~mm}$ ). The vine circulates 50 times in the loop. Mean values of 3 repetitions. 0: Level lower than the SML. ns: non-significant.

\begin{tabular}{|c|c|c|c|c|c|}
\hline \multicolumn{2}{|c|}{ PVC flexible pipe } & {$[\mathbf{D n B P}] \boldsymbol{\mu g} / \mathbf{L}$} & {$[\mathbf{B B P}] \boldsymbol{\mu g} / \mathbf{L}$} & {$[\mathbf{D E H P}] \boldsymbol{\mu g} / \mathbf{L}$} & {$[\mathbf{D I B P}] \boldsymbol{\mu g} / \mathbf{L}$} \\
\hline \multirow{2}{*}{ Pipe 1 New, labelled phtalate-free } & 50 circulations & 0 & 0 & 0 & 0 \\
\cline { 2 - 6 } & 1 transfer (calculation) & 0 & 0 & 0 & 0 \\
\hline \multirow{2}{*}{ Pipe 2 2000s } & 50 circulations & 2 & 13 & 14 & 104 \\
\cline { 2 - 6 } & 1 transfer (calculation) & $\mathrm{ns}$ & $\mathrm{ns}$ & $\mathrm{ns}$ & 2 \\
\hline \multirow{2}{*}{ Pipe 3 1990s } & 50 circulations & 26 & 1402 & 1181 & 4 \\
\cline { 2 - 6 } & 1 transfer (calculation) & $\mathrm{ns}$ & 28 & 23 & $\mathrm{~ns}$ \\
\hline
\end{tabular}

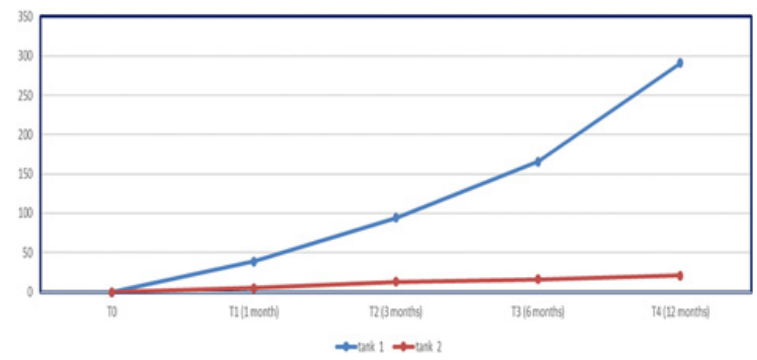

Figure 4. Kinetics of DMP concentration in 2 fiberglass tanks. The first point $\mathrm{T} 0$ corresponds to the sampling just before filling.

complied with regulation because the amount released was under the SML.

In conclusions, there is a risk of confusion between the allegations on the commercial documents and the mentions of attestations of compliance with regulation.

\subsection{Experimentations on polyester tanks reinforced with fiberglass tiles}

Several tests were carried out in real conditions in the cellars.

The results obtained on wines stores 12 months in fiberglass tanks in two fiberglass tanks are presented in the Fig. 4. The tanks released DMP in variable concentration but $\mathrm{C} 1$ was especially contaminating.

This presence of a compound forbidden in the equipment can be explained by the presence in wineries of equipment older than the Regulation (UE) $n^{\circ} 10 / 2011$.

However, such values are not in accordance with the actual regulation and the winemaker had to implement corrective measures.

\subsection{Experimentations on flexible PVC pipes}

Nine different pipes (PVC with and without phthalates, new or old, from different manufacturers) were tested in the laboratory by varying the duration and time of contact with a wine simulant. The analyzes of the synthetic simulants shown an important influence of the temperature on the levels released and fast contaminations (relatively little difference between 10 days and 1 day). The old pipes (before year 2000) all released DnBP, DEHP, BBP, DMP and DIBP in variable concentrations depending on the contact conditions. On the other hand, the two most recent pipes (bought in 2017) released few or no molecules.

Then, cellar trials on a pilot scale, in a closed circuit with wine, confirmed that old PVC pipes can cause phthalate contamination. About 20 to $30 \mu \mathrm{g} / \mathrm{L}$ of BBP and DEHP can be released by circulation (knowing that some wines can be pumped up to twenty times during the process).
Table 6. Reduction by vegetal fibers $(200 \mathrm{~g} / \mathrm{hL})$ and plate and frame filtration.

\begin{tabular}{|c|l|l|}
\hline \multicolumn{2}{|c|}{ Wine 1 } & Wine 2 \\
\hline DnBP & BBP & DBP \\
\hline $84 \%$ & $95 \%$ & $87 \%$ \\
\hline
\end{tabular}

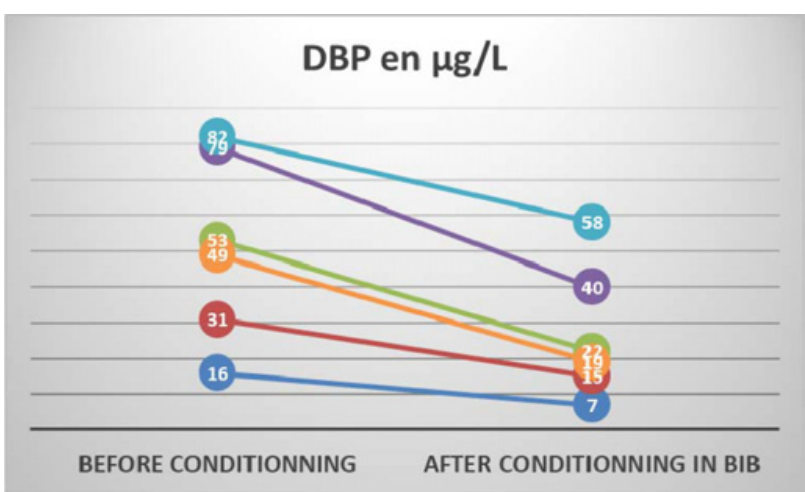

Figure 5. DnBP levels in wines conditioned 6 months in BIB.

Finally, two gravity flow tests were conducted in a cellar to check pipes. A full tank was directly connected to an empty receiving tank in order to overcome the possible contaminations of a pump, and a volume of $5 \mathrm{hL}$ was transferred via $50 \mathrm{~m}$ of connected pipes. A sample was taken in the full departure tank before the flow and another in the receiving tank after the volume has drained. The enrichments in DnBP were around $15 \mu \mathrm{g} / \mathrm{L}$ in both cases. This is not representative but is the example of one method found by some wine-makers to check pipes and of some values that can be observed.

\subsection{Experimentations on filtration process}

Three wines (two of which were intentionally contaminated with phthalates) were filtered through a $20 * 20$ plate filter and a rotating ceramic disc tangential filter.

Significant but very low reductions in DnBP levels (reductions of less than or equal to $30 \%$ ) have been demonstrated Fig. 5. On the other hand, the DEHP content was significantly reduced $(99 \%)$ with a cold filtration. This could explain why this phthalate, although present in particular in certain flexible pipes, is found in fairly few amounts on wine after conditioning.

Potential phthalate contaminations during filtration were not observed during these tests but may be a function of the constituent materials of filters and filter media.

Additional experiments were carried out with plant fibers [4-6] introduced into the tank at the dose of $200 \mathrm{hL}$. 
After an hour of stirring, the wines were filtered on clarifying plates. The results highlighted very significant reductions in DnBP and BBP levels (Table 6).

\subsection{Experimentations on bag-in-box, PET and stoppers}

The packaging of wine in glass or PET (polyethylene terephthalate) bottles didn't result in phthalate enrichment.

About the polyethylene that makes up the bag-in-box, the hypothesis of an adsorption by the pocket was done.

In each instance, after filling, the DnBP level decreased.

\section{Conclusions}

The follow-up of the itineraries and the experiments carried out demonstrated that the materials in contact with wines, in particular plastic materials, could generate significant contaminations in phthalates.

Some equipment as epoxy resin coated tanks, fiberglass reinforced polyester tanks, PVC flexible pipes, could be identified as frequent sources, although the list is certainly not exhaustive.

The risk of contamination also depends on a number of factors, the most important of which is the alcohol content of the wines. Indeed, the risks of migration is very low on musts and at the opposite, very high on alcohol (results not shown). The migration kinetics in tanks clearly demonstrate that the contact time also has a very important impact on the intensity of contamination.

Long ageing in containers "at risk" can lead to levels higher than the LMS. An increase in the temperature of wines, for example during the summer months in poorly isolated cellars or in tanks in height, greatly increases the risk of migration.

Another factor is the contact area between the wine and the material. With PVC and high surface-to-volume ratios, as is the case with flexible pipes, phthalate migration can be very fast and can lead to significant contamination, despite low contact times.

Finally, the degree of wear of equipment or coatings, their integrity, can certainly have an impact, and would require additional studies. There is a cumulative effect until conditioning and few or no reduction of the levels of phthalates was observed except in specific experimentation on vegetal fiber.

Following this study, examples of recommendations can be formulated to limit contamination.

\subsection{Preventive measures}

\subsubsection{Ensure traceability of materials}

Producers should keep the traceability of their materials according to Regulations (CE) $\mathrm{n}^{\circ} 1935 / 2004$ and (UE) $\mathrm{n}^{\circ} 10 / 2011$. The traceability of a material makes it possible to trace the food contact during wine-making and storage, before and after assembly.

It is important to note the dates of purchase, first commissioning, maintenance or repair of each equipment and keep all the documents that can attest to this (certificates of conformity, intervention sheet ...).

The operator should also define the conditions of use of his equipment: type of product (wine, alcohol ...), temperature, duration of contact, single or repeated use ...

\subsubsection{Choose and use equipment without risk of contaminations}

When buying or repairing old equipment, attention should be paid to choose "phthalate-free" materials.

It is strongly discouraged to store wines which degree is over $15-20 \%$ vol or fortified wines in polyester or epoxy coated tanks. Stainless steel should be preferred. Similarly, in the case of mutage, particular attention should be paid to the choice of storage and transfer equipment for the alcohol.

Pipes must be changed regularly, don't wait for them to be damaged or worn out. It is preferable choose "phthalatefree" pipes.

Wine makers should avoid to expose the materials to high temperatures: harvest heating, outside summer storage, storage temperatures over $20^{\circ} \mathrm{C}$

Finally, certain materials could still be used by reassigning them to transfers, or shorter storage duration.

\subsubsection{Ask a declaration of compliance to regulation or to specifications given to the provider}

In Europe, at the marketing stages other than at the retail stage, a written declaration in accordance with Article 16 of Regulation (EC) $\mathrm{n}^{\circ} 1935 / 2004$ shall be available for plastic materials.

They are specifically governed by Regulation (EU) $n^{\circ} 10 / 2011$ which imposes and describes a written declaration of conformity form plastic material.

Specifications can also be given in contract documents by the wine maker.

\subsubsection{Ask and check migration tests and phtalates free attestations}

These tests have to be performed by the providers to check SMLT for every material that intend to come into contact with food. If the material contains phthalates, the provider will also have to check the corresponding SML.

Wine-makers should take care not to confuse the result of a true migration test and a proof of phthalate free material. A migration test can be true while revealing a phthalate migration below the specific migration limit. In this case the material is in accordance with the regulation but can't be labeled "phthalate free".

The producers should take care of materials in order that they don't get damaged. Some suppliers have specific recommendations of use. Using materials as mentioned should be encouraged.

For example, aggressive cleaning and disinfecting procedures (soda concentration $>5 \%$ vol, steam cleaning high pressure washer) mustn't be applied on epoxy coatings.

\subsection{Corrective measures in case of overrun SML}

\subsubsection{Compare the content to ADI}

The legal basis for the safety requirements for a food containing phthalates is Article 14 of the regulation (EC) $\mathrm{n}^{\circ} 178 / 2002$.

This text states that in order to be placed on the market, a foodstuff must neither be harmful to health nor unfit for consumption. These traits are determined on a caseby-case basis through a risk analysis of Admissible Daily Intake (ADI). 
Table 7. Abacus of limits and compliance with regulation according to content in wine for DnBP 0.05 and 0.85 are respectively the average and the maximum value found in our study. 0.3 is MLS. Finally, 1.5 is the level found by some French wine laboratories.

\begin{tabular}{|c|l|l|c|}
\hline Levels in the wine (mg/L) & \% SML & \% ADI & Position \\
\hline 0.05 & 17 & 2 & The wine can be marketed \\
\hline 0.30 & 100 & 13 & \multirow{3}{*}{ The wine can be marketed but phthalates are a hazard to monitor in the cellar } \\
\hline 0.85 & $<$ SML & 37 & \\
\hline 1.50 & $<$ SML & 66 & The wine can't be marketed \\
\hline 2.27 & $<$ SML & 100 & \\
\hline
\end{tabular}

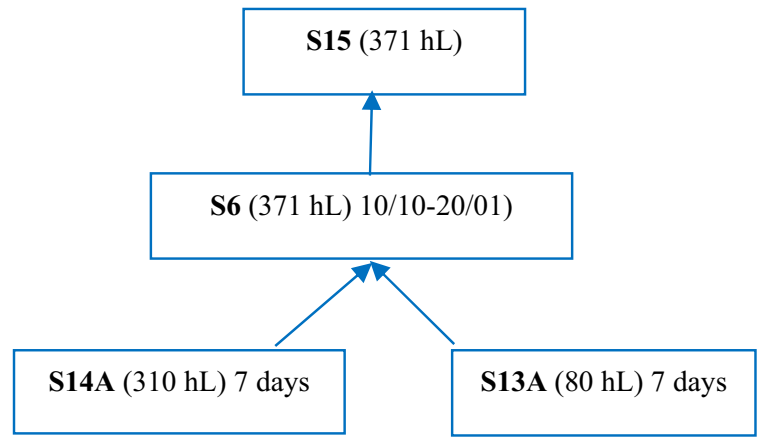

Figure 6. Traceability of equipment for a wine exceeding the SML.

The European Commission, questioned by the French authorities, confirmed that this risk analysis should be conducted when the levels measured in the food exceed the SML established for the substance in the regulation.

If the SML is exceeded but the ADI is not (for the only consumption of wine), the wine can be marketed but phthalates are a danger to monitor in the cellar.

In this case, an investigation must be carried out by the producer, to find the sources of contamination and appropriate measures taken on incriminated materials. In case of ADI overrun, the wine can't be marketed.

An abacus is proposed in Table 7.

\subsubsection{Look for the incriminated material or input.}

This can be done by using traceability of materials, beginning by the contaminated wine.

An example can be developed to look for the contamination of the tank S15 in which a consequent level of DnBP was observed from filling (31/01).

S14A and S13A were "phthalate free" coated tanks and were in contact with wine only for a week. So the S6 intermediate tank was the most probable source.

This was confirmed by adding this tank to the protocol the following year (Fig. 6).

It is also possible to review the potential sources with no predgugement in order to examine the whole process. In case of doubt, for example lack of declaration of compliance or old material, specific investigations should be led.

\subsubsection{Replace highly contaminating equipment}

The equipment identified as impacting significantly phthalate levels should be replaced in priority. It is advised to choose phthalate free materials as far as it is possible. For tanks, it can imply change the equipment or replace the epoxy coating.

\subsection{Prospects}

The formulation of European regulation implies the conformity of the equipment depending on the nature of the material and also on its worst foreseeable contact conditions with food. In wine sector, the time is a factor that can be far more important than in other sectors: up to several month or years of conservation or ageing. As well, longevity of equipment in wineries can be important. We encountered 30 years old materials, visually in perfect conditions and complying with the regulation.

For high migration risk equipment, the first recommendation is to choose phthalate free equipment in a context of renewing. On this base, the problem should be solved gradually over the 10-15 next years.

In the meantime, issues raised by winemakers concern how to use material still in use and containing phthalates, in order to get wines conform to SML or private specifications. This can be done by giving recommendations to affect enhancing factors of migration. An educational brochure is being distributed to French producers.

The challenges ahead are to offer in situ diagnostic tools for old equipment and decision support for the choice of new equipment. Indeed, until now the selling point of epoxy-coating applicators were based on the visual lack of integrity or old coats, but the sanitary "phthalate free" argument is now currently employed to encourage winemakers to cover old epoxy-coatings by new phthalatefree ones.

It is important for producer to get tools to help them know quickly and non-destructive way if their equipment is a proven source of contamination before carrying out such substantial investments.

It is also important to establish a dialogue with the manufacturers of plastic materials to promote materials suitable for the sector. Indeed, the question of the longterm behavior of "phthalate-free" substitution materials can also be an issue.

This study was carried out with the financial support of France Agrimer.

\section{References}

[1] Enquête DGCCRF, BTN-4B-PNE-340GC (2015)

[2] GBPH - Filière vin - Ed. des Journaux officiels. Paris (2017), p. 208

[3] A. Camponovo, C. Riou. BIO Web of Conferences 7, 04001 (2016)

[4] V. Lempereur, C. Louaisil, F. Davaux. Bio Web of Conference 3, 02007 (2014)

[5] M. Grinbaum, C. Puech. Le Vigneron (2018)

[6] OIV resolutions CENO 582/2017et 578/2017 (2017) 